\title{
Malaria Diagnosis and Treatment: Perception of Community Pharmacists in Abuja Metropolis, Nigeria
}

\author{
Emmanuel Peace Chukwuzurum ${ }^{1}$, Ebenezer Obi Daniel ${ }^{1, \text { * }}$, Israel Olukayode Popoola ${ }^{2}$, \\ Paul Olaiya Abiodun ${ }^{1}$, Ahmed Mamuda Bello ${ }^{1}$, Kabir Yunusa Amari ${ }^{3}$, Christie Omolola Adams ${ }^{1}$, \\ Olayinka Victor Ojo ${ }^{1}$, Oladapo Michael Olagbegi ${ }^{4}$, Gabriel Omoniyi Ayeni ${ }^{1}$ \\ ${ }^{1}$ Department of Public Health, Texila American University, Georgetown, Guyana \\ ${ }^{2}$ Department of Epidemiology and Community Health, University of Ilorin, Ilorin, Nigeria \\ ${ }^{3}$ Department of Psychology, Benue State University, Makurdi, Nigeria \\ ${ }^{4}$ South African National Bioinformatics Institute, University of the Western Cape, Cape Town, South Africa
}

Email address:

dannypressy@yahoo.com (E. O. Daniel)

${ }^{*}$ Corresponding author

\section{To cite this article:}

Emmanuel Peace Chukwuzurum, Ebenezer Obi Daniel, Israel Olukayode Popoola, Paul Olaiya Abiodun, Ahmed Mamuda Bello, Kabir Yunusa Amari, Christie Omolola Adams, Olayinka Victor Ojo, Oladapo Michael Olagbegi, Gabriel Omoniyi Ayeni. Malaria Diagnosis and Treatment: Perception of Community Pharmacists in Abuja Metropolis, Nigeria. International Journal of Infectious Diseases and Therapy. Vol. 6, No. 1, 2021, pp. 6-16. doi: 10.11648/j.ijidt.20210601.12

Received: January 21, 2021; Accepted: January 28, 2021; Published: February 9, 2021

\begin{abstract}
Malaria is a life threatening infectious disease that constitutes a major global public health and economic concern. Consequently, the WHO has recommended a T3 initiative (Test, Treat \& Track) to help curb the scourge globally. This study aimed to ascertain the efficacy of malaria diagnosis in malaria case management and perception of community pharmacists on the WHO recommended standard of parasitological diagnosis before commencement of treatment within Abuja metropolis. A descriptive cross sectional study was performed amongst 207 community pharmacists within Abuja Metropolis. Data was obtained through structured, self-administered questionnaire. The association of respondent characteristics with the awareness, practice, and perception of malaria testing, and treatment was evaluated by Chi-square analysis for proportion. Where the number of categories was less than five, Fisher exact test was used. Seventy-two percent (72.9\%) were aware of the WHO recommended T3 initiative on malaria case management. However, less than $10 \%$ of respondents had training in all the three components. On practice, $28.5 \%$ of community pharmacists carry out malaria diagnosis with a confirmatory test before instituting treatment. Ninety-two percent $(92.3 \%)$ treat malaria based on clinical signs and symptoms only. Despite the high rate of clinical diagnosis, a majority (84.1\%) agreed that the confirmatory test is more effective and efficient in malaria case management than clinical diagnosis. Most respondents $(60.4 \%)$ reported that the confirmatory test most readily available was mRDT. Eighty-seven percent $(87 \%)$ have good perception on parasitological confirmatory testing for malaria diagnosis and most respondents have confidence in results from the malaria confirmatory test while $68.6 \%$ trust their malaria confirmatory test skill. A little above half $(52.7 \%)$ of the respondents treat for malaria regardless of negative confirmatory test results when the patient insists on treatment. A higher proportion (39\%) of male community Pharmacists compared to females carry out malaria diagnosis with a confirmatory test before treatment. There was significant association of perception on the efficacy of a parasitological confirmatory test for malaria with age and work experience and there was significant association of work experience with the practice of confirmatory testing before treatment $(\mathrm{P}<0.05)$. Inferentially, this is call to action for government, professional bodies in the health sector and all committed to fight the scourge of malaria for more awareness to the general public on importance of the WHO T3 and capacity strengthening for the frontline health workers - community pharmacy attending to community needs on malaria case management.
\end{abstract}

Keywords: Malaria, WHO T3, Attitude, Practice, Perception 


\section{Introduction}

Malaria is a life-threatening infectious disease that constitutes a major global public health and economic concern. It is a parasitic infection of the red blood cells transmitted to humans through the bite of infected female Anopheles mosquitoes [1]. It is caused by five different species of Plasmodium, namely, P. falciparum, P. vivax, P. malariae, P. knowlesi, and P. ovale. Amongst the five, P. falciparum and $P$. vivax pose the greatest health threat [2]. In 2018, malaria cases were estimated 228 million worldwide and an estimated number of malaria deaths stood at 405000 in 2018. Approximately 106 countries are at risk of transmission of malaria in the world. African Region accounted for $93 \%$ (213 million) of the malaria cases. Six countries accounted for more than half of all malaria cases worldwide: Nigeria (25\%), the Democratic Republic of the Congo (12\%), Uganda (5\%), and Côte d'Ivoire, Mozambique and Niger (4\% each) [3]. Nigeria is a malaria endemic country and accounts for the greater percentage of the world's malaria burden and death. In Nigeria, malaria cases accounts for $30 \%$ of all hospital admissions and about $60 \%$ of all out- patient visits. Annually, about $50 \%$ of Nigerian populations suffer at least one episode of malaria. Malaria is amongst the leading causes of children under-five morbidity and mortality which contributes to $30 \%$ of children under five and $25 \%$ infant mortality. The economic impact of malaria approximates to an annual loss of 132 billion naira in cost of treatment of malaria [4]. This can be measurably reduced if the $\mathrm{WHO} /$ national guidelines on malaria treatment is strictly adhered in performing parasitological testing before appropriate use of arteminsin combination therapy (ACT) for positive cases only.

A great deal of work has been done towards the elimination of malaria across the globe ranging from vector control (use of insecticide-treated mosquito), sulphadoxinepyrimethamine intermittent prophylactic treatment in pregnant mothers yet the malaria scourge has remained a fight to be won especially in Nigeria. The diagnosis of malaria can be by clinical (presumptive) diagnosis, microscopy and rapid diagnostic testing (RDT). Clinical diagnosis is a presumptive method in which treatment of malaria is based on signs and symptoms presented by the patient. It is commonly used due to the fact that it is cheap, rapid in diagnosing, and useful in locations where laboratories are not accessible. Clinical diagnosis suffers the limitation of possible over diagnosis and misdiagnosis of malaria. The microscopy method is the gold standard for malaria diagnosis and involves the use of Giemsa-stained blood sample smear to microscopically detect Plasmodium infected blood cells. This method allows for the detection of infection at asymptomatic and symptomatic stages but drawbacks of cost and technical expertise required to perform. Rapid diagnostic testing involves use of test strips impregnated with monoclonal antibodies to detect targeted antigens in an immunochromatographic assay. RDT is the mainstay of malaria diagnosis in resources constrained areas as minimal cost, technical expertise to perform and interpret test, laboratory equipment is not required. The sensitivity of RDT testing is affected by some factors such as storage condition, temperature, humidity and time of the assay [5]. Incessant and undiagnosed use of available antimalarial medicines has led o the emergence of resistant strains of the Plasmodium parasite, over diagnosis, misdiagnosis and abuse of medicines. The place of screening and diagnosis before treatment of malaria cases cannot be overemphasized hence, in 2010, the World Health Organization (WHO) recommends that all persons of all ages in all epidemiological settings with suspected malaria should receive a parasitological confirmation of diagnosis before commencing treatment [6]. This birthed the shift from presumptive treatment to test based treatment to curb over diagnosis, misdiagnosis and drug resistance issues. Many countries have aligned their malaria case management to the WHO standard of a blood parasitological test before commencement of treatment especially in the public health facilities.

In the public sector, a huge increase in malaria diagnostics has been recorded from less than 10 to over $60 \%$ between 2000 and 2013 in the WHO African Region. However, in the private sector, uptake of malaria diagnostics has remained at much lower levels [7]. In Nigeria just like in most African country, more than $60 \%$ of the population seeks for malaria treatment in private owned drug shops community pharmacies and $29 \%$ proprietary patent medicine vendors) to cut on cost and time spent on waiting for consultation in government or private owned health facilities [8]. Despite the proven effectiveness of malaria diagnosis in malaria case management, community pharmacists still dispense or prescribe antimalarial drugs for patients without malaria diagnosis which could be largely due to their perception on reliability \& accuracy of diagnosis, cost of diagnosis, lack of knowledge on malaria case management policy and guideline, knowledge of causes of fever, patient expectation [9]. This has resulted in over diagnosis, misdiagnosis, under-diagnosis and increased economic burden as more money are spent on treatment of undiagnosed malaria. The emergence of resistant strains of the plasmodium parasite to available arteminsin based combination therapy has further placed financial strain on the economy [10]. The aim of this study was to ascertain the efficacy of malaria diagnosis in malaria case management and perception of community pharmacists on the WHO recommended standard of parasitological diagnosis before commencement of treatment within Abuja metropolis.

\section{Method}

This study was a cross sectional descriptive study, conducted amongst community pharmacists in Abuja Metropolis through the Association of Community Pharmacists' of Nigeria (ACPN) Abuja Chapter. The ACPN is a technical arm of Pharmaceutical Society of Nigeria (PSN) committed to the empowerment of every community 
pharmacist to embrace best pharmacy practice and collaborate with all Stakeholders in the health sector to protect and promote quality healthcare delivery. ACPN activities include Drug Information Service, Advocacy, Capacity building, Members' protection and welfare (ACPN National Secretariat) [11]. The procedure for malaria case management including diagnostic testing and perception to WHO "test, treat\& track (TTT)" mandate was evaluated amongst ACPN members.

A structured self-administered questionnaire was used to collect data in which answers were provided. The questionnaires were administered electronically to individual respondents. The questionnaire consisted of all the study variables. The questionnaire had four sections. Section A comprising of questions on the respondents' demographic data and section $\mathrm{B}$ questions on malaria diagnosis in use for malaria case management and section $\mathrm{C}$ and $\mathrm{D}$ on attitude and practice of community pharmacist towards malaria diagnosis in malaria case management, respectively.

Ethical approval was obtained from the Association of Community Pharmacists of Nigeria, Abuja Chapter and Pharmaceutical Society of Nigeria Abuja Chapter. Each Participant was informed in writing, with full explanation of the content of the questionnaire and the purpose of the study. They were assured the confidentiality of whatever information given by them for the study.

Collected data was analyzed using SPSS software. Descriptive statistics were used to summarize data into frequencies, graphs and tables. Chi-square was used to test for association between various socio-demographic variables and the attitude and practice of the community pharmacist towards malaria diagnosis in case management.

\section{Results}

Section A: Socio-demographic characteristics of participants

The study sample had slightly more male respondents than females, and most respondents (above 80\%) were young adults below the age of 40 years. More than half of the respondents were single, and the majority reported Christianity as their religion. The highest qualification for the majority (above 70\%) of the respondents was the first degree, while the work-related experience was less than 10 years for most (about $80 \%$ ) respondents.

Section B: Community Pharmacists awareness and training on malaria case management

The level of awareness and training of community pharmacists on malaria case management is reflected in Table 2. Most of the respondents $(72.9 \%)$ indicated that they were aware of the WHO recommended T3 (Test (diagnosis), Treat (ACT) \& Track (Reporting)) initiative on malaria case management. Those who indicated that they had been trained in malaria case management were in the majority (67\%). In all, $9 \%$ of respondents had training in all the three components of the WHO T3 initiative on malaria case management.

Table 1. Socio-demographic characteristics of participants.

\begin{tabular}{|c|c|c|c|}
\hline Characteristics & Sub-group & Frequency & Percent \\
\hline \multirow{3}{*}{ Sex } & Female & 94 & 45.4 \\
\hline & Male & 112 & 54.1 \\
\hline & Not indicated & 1 & .5 \\
\hline \multirow{4}{*}{ Age } & less than 30 years & 90 & 43.5 \\
\hline & $30-39$ years & 87 & 42.0 \\
\hline & $40-49$ years & 21 & 10.1 \\
\hline & greater or equal to 50 years & 9 & 4.3 \\
\hline Marital status & Single & 110 & 53.1 \\
\hline \multirow{2}{*}{ Religion } & Christianity & 165 & 79.7 \\
\hline & Islamic & 42 & 20.3 \\
\hline \multirow{2}{*}{ Highest educational qualification } & Graduate Degree & 149 & 72.0 \\
\hline & Postgraduate Degree & 58 & 28.0 \\
\hline \multirow{3}{*}{ Years of experience } & less than 10years & 166 & 80.2 \\
\hline & $10-19$ years & 27 & 13.0 \\
\hline & greater or equal to $30 y e a r s$ & 5 & 2.4 \\
\hline
\end{tabular}

Table 2. Community Pharmacists awareness and training on malaria case management.

\begin{tabular}{|c|c|c|c|}
\hline Assessment question & Response & Frequency & Percent (\%) \\
\hline \multirow{2}{*}{ Knowledge of the WHO recommended T3 initiative } & No & 56 & 27.1 \\
\hline & Yes* & 151 & 72.9 \\
\hline \multirow{2}{*}{ Trained in malaria case management } & No & 67 & 32.4 \\
\hline & Yes* & 138 & 66.7 \\
\hline
\end{tabular}

Trained in Malaria Case Management 


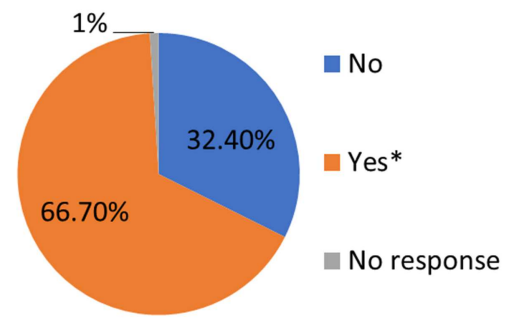

Figure 1. Trained in Malaria Case Management.

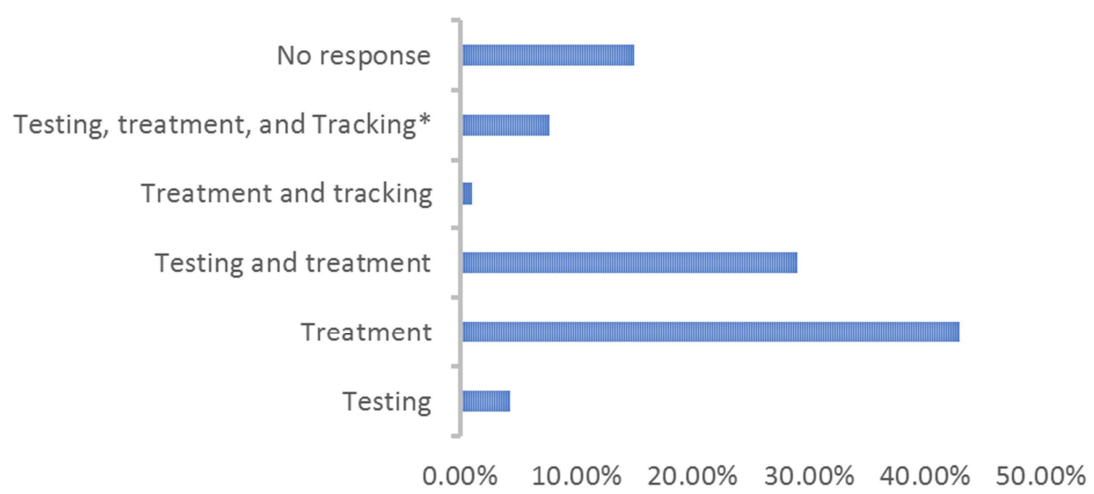

Figure 2. Training on WHO T3 Components.

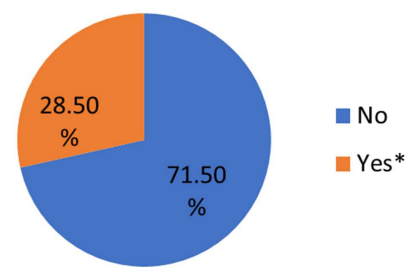

Figure 3. Do you perform confirmatory test before treatment?

Treatment of Malaria based on Clinical diagnosis

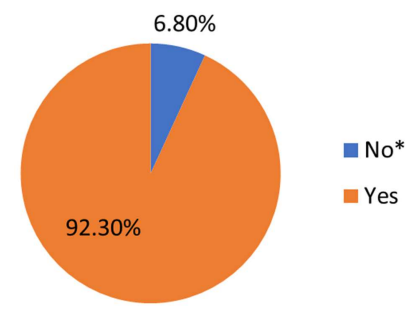

Figure 4. Do you treat malaria based on clinical diagnosis?

Section C: Community Pharmacists practice of and attitude to Malaria diagnosis

The assessment of practice and perception of community pharmacists concerning malaria diagnosis indicated that less than one-third of community pharmacists carry out malaria diagnosis with a confirmatory test before commencing treatment. Malaria Rapid Diagnostic Test (mRDT) and a combination of mRDT and microscopy were the most common confirmatory test carried out. Almost all the respondents (about 92.3\%) indicated that they treat malaria based on clinical signs and symptoms only. Despite the high rate of clinical diagnosis, a majority (about $82.1 \%$ ) agreed that the confirmatory test is more effective and efficient in malaria case management than clinical diagnosis. Most respondents (about $60.4 \%$ ) reported that the confirmatory test most readily available was $\mathrm{mRDT}$.

Performance of Confirmatory Test before Treatment

Section D: Perception of Community Pharmacists on Malaria diagnosis

The perception of community pharmacists towards malaria diagnosis suggests that most community pharmacists (more than $87 \%$ ) do not believe that clinical signs and symptoms only are sufficient in confirming malaria diagnosis, and for treatment initiation. Also, a majority (above 82.6\%) of respondents agreed that a confirmatory test was sufficient in detecting the plasmodium parasite in suspected malaria, and agreed on the need to perform a confirmatory test on suspected malaria cases before treatment. Furthermore, most respondents $(86 \%)$ stated that they have confidence in results from the malaria confirmatory test. However, those that indicated that they trust their skills in performing malaria test were less than $70 \%$. Slightly above half $(52.7 \%)$ of the respondents stated that they would treat for malaria regardless of negative confirmatory test results when the patient insists on treatment.

Need to Perform Malaria Confirmatory testing.

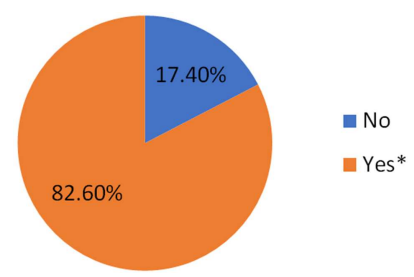

Figure 5. Is there need to perform confirmatory test on suspected malaria case before treatment? 


\section{Confidence in Malaria Confirmatory Test Results}

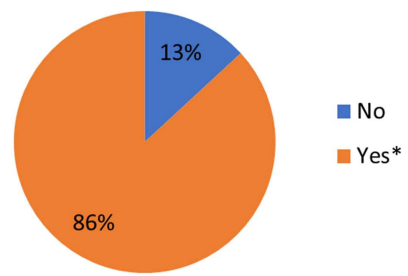

Figure 6. Do you have confidence in malaria confirmatory test results?

\section{Malaria Treatment regardless of Negative Confirmatory Result}

Section E: Association of respondents' characteristics with their practice of and opinion on Malaria diagnosis

Table 3 shows that there were no gender or age-related differences in the opinion of community pharmacists regarding the importance of malaria diagnosis in malaria case management. Similarly, the opinion did not differ significantly between married and unmarried respondents, Christians and Muslims, respondents with graduate and postgraduate qualifications, and between those with less than tens years' work-related experience and those with more years of experience. Additionally, awareness and training in the WHO T3 initiative on malaria case management did not result in a significant difference in the opinion of community pharmacists regarding the importance of malaria diagnosis in malaria case management $(\mathrm{p}<0.05)$.

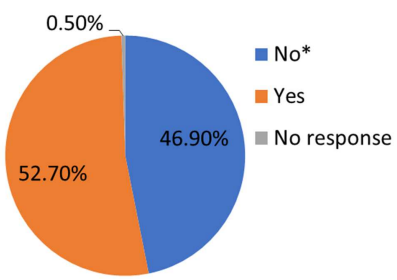

Figure 7. Do you treat for malaria regardless of negative confirmatory test results when the patient insists on treatment?

Table 3. Chi Square analysis showing association between socio-demographic characteristics and importance of malaria test before diagnosis.

\begin{tabular}{|c|c|c|c|c|}
\hline \multirow{2}{*}{ Respondents characteristics } & \multicolumn{2}{|c|}{ Response } & \multirow{2}{*}{ Chi-square } & \multirow{2}{*}{$P$ value } \\
\hline & No $(\%)$ & Yes $(\%)$ & & \\
\hline \multicolumn{5}{|l|}{ Sex } \\
\hline Female & 10.64 & 84 & \multirow{2}{*}{3.257} & \multirow{2}{*}{0.071} \\
\hline Male & 19.82 & 89 & & \\
\hline \multicolumn{5}{|l|}{ Age (Years) } \\
\hline Less than 30 years & 11.24 & 88.76 & \multirow{2}{*}{2.25} & \multirow{2}{*}{0.325} \\
\hline 40 and above & 20 & 80 & & \\
\hline \multicolumn{5}{|l|}{ Marital status } \\
\hline Married & 16.49 & 83.51 & \multirow{2}{*}{0.129} & \multirow{2}{*}{0.719} \\
\hline Single & 14.68 & 85.32 & & \\
\hline \multicolumn{5}{|l|}{ Level of Education } \\
\hline Graduate & 15.54 & 84.46 & 0 & 0.997 \\
\hline \multicolumn{5}{|l|}{ Religion } \\
\hline Christianity & 13.41 & 86.59 & \multirow{2}{*}{2.754} & \\
\hline Islamic & 23.81 & 76.19 & & \\
\hline \multicolumn{5}{|l|}{ Years of experience } \\
\hline Less than 10 years & 13.94 & 86.06 & \multirow{2}{*}{1.607} & \multirow{2}{*}{0.205} \\
\hline 10 and above & 21.95 & 78.05 & & \\
\hline \multicolumn{5}{|c|}{ Knowledge of WHO recommended T3 initiative } \\
\hline No & 23.64 & 76.36 & \multirow{2}{*}{3.754} & \multirow{2}{*}{0.053} \\
\hline Yes & 12.58 & 87.42 & & \\
\hline \multicolumn{5}{|c|}{ Trained in malaria case management } \\
\hline No & 18.18 & 81.82 & \multirow{2}{*}{0.459} & \multirow{2}{*}{0.498} \\
\hline Yes & 14.49 & 85.51 & & \\
\hline \multicolumn{5}{|l|}{ Trained in malaria Testing } \\
\hline No & 20.88 & 79.12 & 2.653 & 0.103 \\
\hline
\end{tabular}

Association between respondents' characteristics and practice of WHO T3 components

A significantly higher proportion $(88.24 \%)$ of those who had received Training in testing practiced all three components (Testing, treatment, and tracking) of the WHO T3 initiative on malaria case management (Table 6). Other respondents' characteristics were not significantly associated with the practice of all the three components of the WHO T3 initiative on malaria case management. 
Table 4. Association between respondents' characteristics and practice of WHO T3 components.

\begin{tabular}{|c|c|c|c|c|}
\hline \multirow{2}{*}{ Respondent's characteristics } & \multicolumn{2}{|l|}{ Response } & \multirow{2}{*}{ Chi-square } & \multirow{2}{*}{ P value } \\
\hline & One or two (\%) & All three (\%) & & \\
\hline \multicolumn{5}{|l|}{ Sex } \\
\hline Female & 97.87 & 2.13 & 2.079 & 0.149 \\
\hline \multicolumn{5}{|l|}{ Age } \\
\hline less than 30 & 96.67 & 3.33 & \multirow[b]{2}{*}{0.707} & \multirow[b]{2}{*}{0.702} \\
\hline $30-39$ & 94.25 & 5.75 & & \\
\hline \multicolumn{5}{|l|}{ Marital status } \\
\hline Married & 95.88 & 4.12 & \multirow{2}{*}{0.022} & \multirow{2}{*}{0.882} \\
\hline Single & 95.45 & 4.55 & & \\
\hline \multicolumn{5}{|l|}{ Level of education } \\
\hline Graduate & 97.32 & 2.68 & \multirow{3}{*}{3.537} & \multirow{3}{*}{0.06} \\
\hline Post Graduate & 91.38 & 8.62 & & \\
\hline \multicolumn{3}{|l|}{ Religion } & & \\
\hline Christianity & 96.36 & 3.64 & 0.99 & 0.32 \\
\hline \multicolumn{5}{|l|}{ Years of experience } \\
\hline Less than 10 & 95.18 & 4.82 & \multirow{2}{*}{0.448} & \multirow{2}{*}{0.503} \\
\hline 10 and above & 7.56 & 2.44 & & \\
\hline \multicolumn{5}{|c|}{ Knowledge of WHO recommended $\mathrm{T} 3$ initiative } \\
\hline No & 98.21 & 1.79 & \multirow{2}{*}{0.271} & \multirow{2}{*}{0.271} \\
\hline Yes & 94.7 & 5.3 & & \\
\hline \multicolumn{5}{|c|}{ Trained on malaria case management } \\
\hline No & 95.52 & 4.48 & \multirow{2}{*}{0.002} & \\
\hline Yes & 95.65 & 4.35 & & \\
\hline \multicolumn{5}{|l|}{ Trained on malaria Testing } \\
\hline No & 100 & 0 & \multirow{2}{*}{$0.003 *$} & \\
\hline Yes & 90.59 & 9.41 & & \\
\hline
\end{tabular}

Table 5. Association between respondents' characteristics and the practices of confirmatory malaria diagnosis before treatment initiation.

\begin{tabular}{|c|c|c|c|c|}
\hline \multirow{2}{*}{ Respondent's characteristics } & \multicolumn{2}{|c|}{ Response } & \multirow{2}{*}{ Chi-square } & \multirow{2}{*}{ P value } \\
\hline & No (\%) & Yes $(\%)$ & & \\
\hline \multicolumn{5}{|l|}{ Sex } \\
\hline Female & 79.79 & 20.21 & \multirow{3}{*}{5.392} & \multirow{3}{*}{$0.02 * *$} \\
\hline Male & 65.18 & 34.82 & & \\
\hline \multicolumn{3}{|l|}{ Age } & & \\
\hline Less than 30 years & 71.11 & 28.89 & \multirow{3}{*}{0.059} & \multirow{3}{*}{0.971} \\
\hline $30-39$ & 71.26 & 28.74 & & \\
\hline 40 and above & 73.33 & 26.67 & & \\
\hline \multicolumn{5}{|l|}{ Marital status } \\
\hline Married & 74.23 & 25.77 & \multirow{2}{*}{0.667} & \multirow{2}{*}{0.414} \\
\hline Single & 69.09 & 30.91 & & \\
\hline \multicolumn{5}{|l|}{ Level of Education } \\
\hline Graduate & 73.15 & 26.85 & \multirow{2}{*}{0.716} & \multirow{2}{*}{0.397} \\
\hline Post graduate & 67.24 & 32.76 & & \\
\hline \multicolumn{5}{|l|}{ Religion } \\
\hline Christianity & 73.33 & 26.67 & \multirow{2}{*}{1.345} & \multirow{2}{*}{0.246} \\
\hline Islamic & 64.29 & 35.71 & & \\
\hline \multicolumn{5}{|l|}{ Years of experience } \\
\hline Less than 10years & 71.08 & 8.92 & \multirow{2}{*}{0.07} & \multirow{2}{*}{0.791} \\
\hline 10 and above & 73.17 & 26.83 & & \\
\hline \multicolumn{5}{|c|}{ Knowledge of $\mathrm{WHO}$ recommended $\mathrm{T} 3$ initiative } \\
\hline No & 89.29 & 10.71 & \multirow{2}{*}{11.92} & \multirow{2}{*}{$0.001 * *$} \\
\hline Yes & 64.9 & 35.1 & & \\
\hline \multicolumn{5}{|c|}{ Trained on malaria case management } \\
\hline No & 77.61 & 22.39 & \multirow{2}{*}{1.984} & \multirow{2}{*}{0.159} \\
\hline Yes & 68.12 & 31.88 & & \\
\hline \multicolumn{5}{|l|}{ Trained on malaria Testing } \\
\hline No & 75.82 & 24.18 & \multirow{2}{*}{4.389} & \multirow{2}{*}{$0.036 * *$} \\
\hline Yes & 61.18 & 38.82 & & \\
\hline
\end{tabular}


Association between respondents' characteristics and the practices of confirmatory malaria diagnosis before treatment initiation

Table 5 shows that a higher proportion of male community Pharmacists compared to females carry out malaria diagnosis with a confirmatory test before treatment. In addition, a significantly higher proportion (35.1\%) of those who know about the WHO recommended T3 initiative on malaria case management as well as those who had received training on malaria testing (33\%) reported carrying out malaria diagnosis with a confirmatory test before treatment when compared to those who are not aware and have not been trained $(\mathrm{p}<0.05)$.

Section F: Factors associated with the perception of community pharmacists on malaria diagnosis

The results summarized in Table 6 indicates perception of confirmatory test (parasitological testing) to be more effective and efficient in malaria diagnosis than clinical diagnosis was higher among younger Pharmacists those aged $<30$ years $(92.22 \%)$, followed by those aged $30-39$ $(82.76 \%)$, compared to those aged 40 years and above (65.52\%). Similarly, a significantly higher proportion of those with less than 10 years' work-related experience compared to those with more work experience had the perception that a confirmatory test was more effective and efficient in malaria case management than clinical diagnosis.

Table 6. Association of respondents' characteristics with the perception of the effectiveness and efficiency of the confirmatory test compared to clinical diagnosis in malaria case management.

\begin{tabular}{|c|c|c|c|c|}
\hline \multirow{3}{*}{ Respondent's characteristic } & \multicolumn{2}{|c|}{ Response } & \multirow{3}{*}{ Chi-square } & \multirow{3}{*}{$P$ value } \\
\hline & No & Yes* & & \\
\hline & $(\%)$ & $(\%)$ & & \\
\hline \multicolumn{5}{|l|}{ Sex } \\
\hline Female & 15.05 & 84.95 & \multirow{2}{*}{0.04} & \multirow{2}{*}{0.842} \\
\hline Male & 16.07 & 83.93 & & \\
\hline \multicolumn{5}{|l|}{ Age (Years) } \\
\hline Less than 30 & 7.78 & 92.22 & \multirow{3}{*}{12.256} & \multirow{3}{*}{$0.002 * *$} \\
\hline $30-39$ & 17.24 & 82.76 & & \\
\hline 40 and above & 34.48 & 65.72 & & \\
\hline \multicolumn{5}{|l|}{ Marital status } \\
\hline Married & 17.71 & 82.29 & \multirow[b]{2}{*}{0.648} & \multirow[b]{2}{*}{0.421} \\
\hline Single & 13.64 & 86.36 & & \\
\hline \multicolumn{5}{|l|}{ Level of Education } \\
\hline Graduate & 14.09 & 85.91 & \multirow{2}{*}{0.851} & \multirow{2}{*}{0.356} \\
\hline Post graduate & 19.3 & 80.7 & & \\
\hline \multicolumn{5}{|l|}{ Religion } \\
\hline Christianity & 15.24 & 84.76 & \multirow{2}{*}{0.052} & \multirow{2}{*}{0.82} \\
\hline Islamic & 16.67 & 83.33 & & \\
\hline \multicolumn{5}{|l|}{ Years of experience } \\
\hline Less than 10 & 10.84 & 89.16 & \multirow{2}{*}{14.335} & \multirow{2}{*}{$<0.001 * *$} \\
\hline 10 and above & 35 & 65 & & \\
\hline \multicolumn{5}{|c|}{ Knowledge of WHO recommended initiative } \\
\hline No & 17.86 & 82.14 & \multirow{2}{*}{0.316} & \multirow{2}{*}{0.574} \\
\hline Yes & 14.67 & 85.33 & & \\
\hline \multicolumn{5}{|c|}{ Trained on malaria case management } \\
\hline No & 16.42 & 83.58 & \multirow{2}{*}{0.04} & \multirow{2}{*}{0.841} \\
\hline Yes & 15.33 & 84.67 & & \\
\hline \multicolumn{5}{|l|}{ Trained in malaria testing } \\
\hline No & 21.11 & 78.89 & \multirow{2}{*}{2.762} & \multirow{2}{*}{0.097} \\
\hline Yes & 11.76 & 88.24 & & \\
\hline
\end{tabular}

Association between respondents' characteristics and test confidence in results from the malaria confirmatory test

There was no gender, age, marital status, and religious affiliation related association in the confidence of respondents regarding malaria test results. Also, work experience and training in the WHO T3 initiative on malaria case management did not result in a significant difference in the confidence community pharmacists have in the results of malaria confirmatory test (Table 7).

Association between respondents' characteristics and respondent's confidence in performing malaria confirmatory

The confidence of community Pharmacists to perform a malaria confirmatory test is shown in Table 8. More males compared with females, and those aware of the WHO T3 initiative on malaria case management compared to those not aware have more confidence in their skills to perform malaria confirmatory test. Similarly, those trained in malaria case management compared to those not trained, as well as those who had training in malaria testing compared with those not trained reported that they have more confidence to perform malaria confirmatory test. 
Table 7. Association between respondents' characteristics and confidence in results from the malaria confirmatory test.

\begin{tabular}{|c|c|c|c|c|}
\hline \multirow{2}{*}{$\begin{array}{l}\text { Respondent's characteristics } \\
\text { Sex }\end{array}$} & \multicolumn{2}{|c|}{ Response No (\%) Yes (\%) } & \multirow[t]{2}{*}{ Chi-square } & \multirow[t]{2}{*}{ Pvalue } \\
\hline & & & & \\
\hline Female & 14.89 & 85.11 & \multirow{3}{*}{0.417} & \multirow{3}{*}{0.518} \\
\hline Male & 11.82 & 88.18 & & \\
\hline \multicolumn{3}{|l|}{ Age (years) } & & \\
\hline Less than 30 & 13.33 & 86.67 & \multirow{3}{*}{0.601} & \multirow{3}{*}{0.74} \\
\hline $30-39$ & 11.63 & 88.37 & & \\
\hline 40 and above & 17.24 & 82.76 & & \\
\hline \multicolumn{5}{|l|}{ Marital status } \\
\hline Married & 13.68 & 86.32 & \multirow{2}{*}{0.041} & \multirow{2}{*}{0.84} \\
\hline Single & 12.73 & 87.27 & & \\
\hline \multicolumn{5}{|l|}{ Level of education } \\
\hline Graduate & 15.65 & 84.35 & \multirow{2}{*}{2.784} & \multirow{2}{*}{0.095} \\
\hline Postgraduate & 6.9 & 93.1 & & \\
\hline \multicolumn{5}{|l|}{ Religion } \\
\hline Christianity & 12.27 & 87.73 & \multirow{2}{*}{0.565} & \multirow{2}{*}{0.452} \\
\hline Islamic & 16.67 & 83.33 & & \\
\hline \multicolumn{5}{|l|}{ Years of experience } \\
\hline Less than 10 & 12.12 & 87.88 & \multirow{2}{*}{0.814} & \multirow{2}{*}{0.367} \\
\hline 10 and above & 17.5 & 82.5 & & \\
\hline \multicolumn{5}{|c|}{ Knowledge of $\mathrm{WHO}$ recommended $\mathrm{T} 3$ initiative } \\
\hline No & 17.86 & 82.14 & \multirow{2}{*}{1.48} & \multirow{2}{*}{0.224} \\
\hline Yes & 11.41 & 88.59 & & \\
\hline \multicolumn{5}{|c|}{ Trained in malaria case management } \\
\hline No & 16.67 & 83.33 & \multirow[b]{2}{*}{0.961} & \multirow[b]{2}{*}{0.327} \\
\hline Yes & 11.68 & 88.32 & & \\
\hline \multicolumn{5}{|l|}{ Trained in malaria Testing } \\
\hline No & 11.11 & 88.89 & \multirow{2}{*}{0.137} & \multirow{2}{*}{0.711} \\
\hline Yes & 9.41 & 90.59 & & \\
\hline
\end{tabular}

Table 8. Association between respondents' characteristics and respondent's confidence in performing malaria confirmatory test.

\begin{tabular}{|c|c|c|c|c|}
\hline \multirow{2}{*}{ Respondent's characteristics } & \multicolumn{2}{|c|}{ Response } & \multirow{2}{*}{ Chi-square } & \multirow{2}{*}{$P$ value } \\
\hline & No $(\%)$ & Yes*(\%) & & \\
\hline \multicolumn{5}{|l|}{ Sex } \\
\hline Female & 36.67 & 63.33 & \multirow{3}{*}{6.105} & \multirow{2}{*}{$0.013 * *$} \\
\hline Male & 20.75 & 79.25 & & \\
\hline \multicolumn{4}{|l|}{ Age (Years) } & \\
\hline Less than 30 & 25.58 & 74.42 & \multirow{3}{*}{0.415} & \\
\hline 30-39 & 29.76 & 70.24 & & \multirow{2}{*}{0.813} \\
\hline 40 and above & 29.63 & 70.37 & & \\
\hline \multicolumn{5}{|l|}{ Marital status } \\
\hline Married & 25.27 & 74.73 & \multirow{2}{*}{0.588} & \multirow{2}{*}{0.443} \\
\hline Single & 30.19 & 69.81 & & \\
\hline \multicolumn{5}{|l|}{ Levels of education } \\
\hline Graduate & 29.29 & 70.71 & \multirow[b]{2}{*}{0.449} & \multirow[b]{2}{*}{0.053} \\
\hline Postgraduate & 24.56 & 75.44 & & \\
\hline \multicolumn{5}{|l|}{ Religion } \\
\hline Christianity & 30.32 & 69.68 & \multirow{2}{*}{2.087} & \multirow{2}{*}{0.149} \\
\hline Islamic & 19.05 & 80.95 & & \\
\hline \multicolumn{5}{|l|}{ Years of experience } \\
\hline Less than 10 & 26.25 & 73.75 & \multirow{2}{*}{1.179} & \multirow[b]{2}{*}{0.278} \\
\hline 10 and above & 35.14 & 64.86 & & \\
\hline \multicolumn{5}{|c|}{ Knowledge of WHO recommended T3 initiative } \\
\hline No & 45.28 & 54.72 & \multirow{2}{*}{10.864} & \multirow{2}{*}{$0.001 * *$} \\
\hline Yes & 21.53 & 78.47 & & \\
\hline \multicolumn{5}{|c|}{ Trained in malaria case management } \\
\hline No & 38.46 & 61.54 & \multirow{2}{*}{5.065} & \multirow{2}{*}{$0.024 * *$} \\
\hline Yes & 23.08 & 76.92 & & \\
\hline \multicolumn{5}{|l|}{ Trained in malaria Testing } \\
\hline No & 42.35 & 57.65 & \multirow{2}{*}{19.02} & \multirow{2}{*}{$<0.001 *$} \\
\hline Yes & 12.2 & 72 & & \\
\hline
\end{tabular}




\section{Discussion}

The study sample had slightly more male respondents than females, and most respondents (above 80\%) were young adults below the age of 40 years. The highest qualification for the majority (above 70\%) of the respondents was the first degree, while the work-related experience was less than 10 years for most (about $80 \%$ ) respondents, this is supported by a study done by Kanayo Patrick Osemene and Wilson $\mathrm{O}$ Erhun [12] in which there were more male than females within the age 18-34 years in community pharmacies. More than half of the respondents were married, and the majority reported Christianity as their religion. The long work hours and demanding nature of community pharmacy may explain why there are more young (below 40 years) male than female pharmacists in community pharmacies.

More than half of the respondents $(72.9 \%)$ indicated that they were aware of the WHO recommended T3 (Test (diagnosis), Treat (ACT) \& Track (Reporting)) initiative on malaria case management. Those who indicated that they had been trained in malaria case management were in the majority (67\%). This number falls within the number that have received training on one or two WHO T3 initiative commonly on testing. In all, only $9 \%$ of respondents had training in all the three components of the WHO T3 initiative on malaria case management. The study by Ndibuagu et al [13], in which $90.7 \%$ of respondents were aware of parasitological examination of blood to be the WHO recommended approach of establishing malaria diagnosis corroborates this finding from current research. Also a study done by Usman Rabi et al [14] reported more than half of respondents had good knowledge of mRDT in tandem with above finding. This calls for training of community pharmacist on the WHO T3 initiative as community pharmacist will be better equipped with knowledge to handle malaria case management.

The findings from this study which revealed that $28.5 \%$ of community pharmacists carry out malaria diagnosis with a confirmatory test before commencing treatment and $90 \%$ of the respondents indicated that they treat malaria based on clinical signs and symptoms only (presumptive/ syndromic treatment) is substantiated by results of a study conducted by Uzochukwu et al [15] in South Eastern Nigeria which reported that majority of health facilities practiced presumptive malaria case management. In contrast, a study conducted by Usman Rabi et al [14] on availability and use of mRDT in public health facilities reported $82.7 \%$ of the healthcare workers employed malaria RDT routinely before making a diagnosis of malaria This may be largely due to public health facilities are less likely to commence treatment without diagnosis than private owned pharmacies which are profit-oriented. Malaria Rapid Diagnostic Test (mRDT) and a combination of mRDT and microscopy were the most common confirmatory test carried out. Most respondents $(60.4 \%)$ reported that the confirmatory test most readily available was mRDT. Use of laboratory microscopy was relatively low as seen also in previous studies $[15,16]$. In spite of being regarded as the gold standard for malaria diagnosis; use of microscopy is low which is a positive development as it connotes wide acceptability of RDTs among the health workers. Despite the high rate of clinical diagnosis, a majority $(84.1 \%)$ agreed that the confirmatory test is more effective and efficient in malaria case management than clinical diagnosis.

$87 \%$ community pharmacists do not believe that clinical signs and symptoms only are sufficient in confirming malaria diagnosis, and for treatment initiation. Also, a majority $(82.6 \%)$ of respondents agreed that a confirmatory test was sufficient in detecting the plasmodium parasite in suspected malaria, and agreed on the need to perform a confirmatory test on suspected malaria cases before treatment. This is in line with findings from previous study by Ndibuagu et al [13], where it was reported that $64 \%$ of healthcare providers thought it was important to perform a confirmatory diagnosis before commencing treatment, $70.9 \%$ opined that presumptive diagnosis of malaria is not a better way of making diagnosis and $76.7 \%$ did not believe malaria diagnosis is always clear on listening to the patient. In contrast Izuchukwu Frank Obi et al [17] noted poor perception of healthcare workers on mRDT that resulted in prescription of ACTs to negative cases though over $90 \%$ agreed that febrile patients should be tested before commencement of treatment. Most of the respondents stated that they have confidence in results from the malaria confirmatory test, this is supported study by Izuchukwu Frank Obi et al [17], showed that more than $80 \%$ of respondent said they fully trust a positive mRDT. However, those that indicated that they trust their skills in performing malaria test were less than $70 \%$.

This study revealed that, there are no significant impact of socio-demographic characteristic on community pharmacists' practice of and opinion on malaria diagnosis. Furthermore, awareness and training in the WHO T3 initiative on malaria case management did not result in a significant difference in the opinion of community pharmacists regarding the importance of malaria diagnosis in malaria case management. Majority of the respondent who indicated to have been trained did so for just testing which may not be a sufficient exposure to inform change in a practice. A holistic training on WHO (testing, treating and tracking) malaria case management will help community pharmacist better appreciate the importance of practicing the WHO T3. Similarly, in a study by Izuchukwu Frank Obi et al [17] amongst health workers in Ebonyi state revealed that respondents socio-demographic characteristics did not impact significantly on health workers practice of malaria diagnosis. However, in this study it was discovered that significantly higher proportion of those who had received Training in testing practiced all three components (Testing, Treatment, and Tracking) of the WHO T3 initiative on malaria case management.

Also, a higher proportion of male community Pharmacists compared to females carry out malaria diagnosis with a 
confirmatory test before treatment. In addition, a significantly higher proportion of those aware of the WHO recommended $\mathrm{T} 3$ initiative on malaria case management as well as those who had received training on malaria testing compared to those who are not aware and have not been trained reported carrying out malaria diagnosis with a confirmatory test before treatment.

Younger community pharmacists (<30years) and also significantly higher proportion of those with less than 10 years' work-related experience showed good perception of malaria confirmatory test. A similar study carried out in Thailand by Manas Kotepui et al [18] among health workers corroborates this finding in which good perception of malaria detection to be higher in health workers 20-29yrs of age and with less than 10 years' experience in support of the findings from this research. This could be due to improvement in awareness of and adoption of the WHO recommended malaria case management by countries especially in curriculums for health workers in training. Though there has been a rise in awareness of importance, yet more work needs to be done in ensuring that perception and knowledge translate into practice as a significantly higher proportion of respondents with less than 10 years' work experience think (possibly still practices) that clinical signs and symptoms only are sufficient in confirming malaria diagnosis and treatment.

There was no significant association of respondents' characteristics to their prescribing ACT for negative RDT test results. This contrast a study by Izuchukwu Frank Obi et al [17], which reported prescriber's professional cadre, perception of RDT, training on other causes of fever and health facility level to be significantly associated with ACT prescription to patients with negative RDT results. Prescription of ACTs to negative results may be due to lack of trust for a negative confirmatory result for malaria diagnosis as truly ruling out malaria, poor perception of confirmatory test to detect plasmodium parasite [17], to please patient or not to be seen as incompetent [19].

\section{Conclusion}

Findings from this study revealed that community pharmacists within Abuja Metropolis have good perception towards malaria diagnosis in that most community pharmacists do not believe in clinical diagnosis is sufficient for malaria diagnosis, and for treatment initiation rather that a parasitological confirmatory test should be performed in suspected malaria cases as recommended by WHO for malaria case management. Knowledge of malaria testing is good but there seem to exist knowledge gap in proper treatment and tracking of malaria cases. Furthermore, on malaria diagnosis, most respondents stated that they have confidence in results from the malaria confirmatory test. However, the gap lies in the practice, as not all trust their skills in performing malaria test and more than half of the respondents stated that they would treat for malaria regardless of negative confirmatory test results when the patient insists on treatment. This is so a call to action for government, professional bodies in the health sector and all committed to fighting the scourge of malaria for more awareness to the general public on importance of the WHO T3 and capacity strengthening for the frontline health workers - community pharmacy attending to community needs on malaria case management.

\section{References}

[1] Ukaegbu C. O, Nnachi A. U, Mawak J. D, Igwe C. C. (2014). Incidence of Concurrent Malaria and Typhoid Fever Infections in Febrile Patients in Jos, Plateau State Nigeria. International Journal of Scientific and Technology Research. 3 (4): 157-161.

[2] Tangpukdee, N., Duangdee, C., Wilairatana, P., \& Krudsood, S. (2009). Malaria diagnosis: a brief review. The Korean journal of parasitology, 47 (2), 93-102. https://doi.org/10.3347/kjp.2009.47.2.93.

[3] Wongsrichanalai C, Barcus MJ, Muth S, Sutamihardja A, Wernsdorfer WH (2007). A Review of Malaria Diagnostic Tools: Microscopy and Rapid Diagnostic Test (RDT) In: Breman JG, Alilio MS, White NJ, editors. Defining and Defeating the Intolerable Burden of Malaria III: Progress and Perspectives: Supplement to Volume 77 (6) of American Journal of Tropical Medicine and Hygiene. Northbrook (IL): American Society of Tropical Medicine and Hygiene.

[4] Jimoh A, Sofola O, Petu A, Okorosobo T (2007) Quantifying the economic burden of malaria in Nigeria using the willingness to pay approach. Cost effectiveness resource allocation-published online 5 [PMC free article] [PubMed] [Google Scholar].

[5] WHO Malaria diagnosis and Treatment Guideline.

[6] WHO (2010) World malaria report, 2010.

[7] WHO (2014) World malaria report, 2014.

[8] Isiguzo C, Anyanti J, Ujuju C, Nwokolo E, De La Cruz A, Schatzkin E, et al. (2014) Presumptive Treatment of Malaria from Formal and Informal Drug Vendors in Nigeria. PLoS $\begin{array}{llll}\text { ONE } & 9 & (10): & \text { el10361. }\end{array}$ https://doi.org/10.1371/journal.pone.0110361.

[9] Kabaghe, A. N., Visser, B. J., Spijker, R. et al. Health workers compliance to rapid diagnostic tests (RDTs) to guide malaria treatment: a systematic review and meta-analysis. Malar $J 15$, 163 (2016). https://doi.org/10.1186/s12936-016-1218-5.

[10] Hume JC, Barnish G, Mangal T, Armázio L, Streat E, Bates I (2008): Household cost of malaria overdiagnosis in rural Mozambique. Malar J., 7: 33-10.1186/1475-2875-7-33.

[11] Association of Community Pharmacist of Nigeria official website.

[12] Osemene, Kanayo Patrick and Erhun, Wilson Oyekigho (2018). Evaluation of community pharmacists' involvement in public health activities in Nigeria. Braz. J. Pharm. Sci. [online], vol. 54, n. 3.

[13] Ndibuagu, E. O., Amadi, O. F. and Ugwu, E. T. (2017) Knowledge and Perception of Malaria Rapid Diagnostic Test among Medical Doctors in a South Eastern Nigeria Tertiary Hospital. Journal of Biosciences and Medicines, 5, 1-16. 
[14] Usman R, Umar AA, Gidado S, Gobir AA, Obi IF, Ajayi I, Ajumobi O. (2018) Predictors of malaria Rapid Diagnostic Tests' utilisation among healthcare workers in Zamfara State. PLoS ONE 13 (12).

[15] Benjamin SCU, Emmanuel O, Nkoli NE, Ogochukwu PE, Miriam OA, Florence T.(2011) Improving Rational Treatment of Malaria: Perceptions and Influence of RDTs on Prescribing Behaviour of Health Workers in Southeast Nigeria. PLoS One; 6 (1): e14627.

[16] Meremikwu M, Okomo U, Nwachukwu C, Oyo-Ita A, EkeNjoku J, Okebe J, Oyo-Ita E, Garner P (2007): Anti-malarial drug prescribing practice in private and public facilities in south-east Nigeria: a descriptive study. Malar J, 6: 55.
[17] Obi IF, Sabitu K, Olorukooba A, Adebowale AS, Usman R, Nwokoro U, Ajumobi O, Idris S, Nwankwo L, Ajayi O. O (2019) Health workers' perception of malaria rapid diagnostic test and factors influencing compliance with test results in Ebonyi state, Nigeria. PLoS ONE 14 (10): e0223869. https://doi.org/10.1371/journal.pone.0223869.

[18] Kwuntida U Kotepui, Manas Kotepui, Chuchard Punsawad (2019); Knowledge, Attitude and Practice Related to Malaria diagnosis among Health Workers in Hospitals: across sectional survey. Journal of Tropical Medicine Volume 2019. https://doi.org/10.1155/2019/1414079.

[19] Chandler CIR, Mangham L, Njei AN, Achonduh O, Mbacham WF, Wiseman V: (2012) "As a clinician, you are not managing. 